\title{
Statistical Inferences Regarding the Genetic Determinism of the Embryo-Fetal Losses
}

\author{
Dana Liana PUSTA ${ }^{1}$, Rodica SOBOLU ${ }^{2}$, Ioana Pop ${ }^{2}$ \\ ${ }^{1}$ Faculty of Veterinary Medicine, University of Agricultural Sciences and Veterinary Medicine Cluj- \\ Napoca, Romania \\ ${ }^{2}$ Faculty of Horticulture, University of Agricultural Sciences and Veterinary Medicine Cluj-Napoca, Romania. \\ *corresponding author: dana.pusta@usamvcluj.ro
}

Bulletin UASVM Veterinary Medicine 71(2) / 2014,

Print ISSN 1843-5270; Electronic ISSN 1843-5378

DOI:10.15835/buasvmcn-vm: 10344

\begin{abstract}
The purpose of this study is to examine the way in which embryonic mortality and fetal abortions are inherited from mother to offspring. The regression method of offspring on dam was used in order to measure the genetic and environmental relationships among considered characters. The results point that the abortion rate is higher in cows which have already had abortions during their lives. The one-way Anova analysis shows the existence of influence from breeding males as well. In the case of embryonic mortality, a strong genetic determinism $\left(\mathrm{h}^{2}=0.43\right)$ was obtained, while in the case of fetal abortions there was found a low genetic determinism $\left(\mathrm{h}^{2}=0.35\right)$. Heritability was estimated starting from the regression of offspring on parents. Statistic data were obtained using linear regression option from Rcmdr package in R statistics software.
\end{abstract}

Key words: embryonic mortality, fetal abortion, inheritance, regression method, R-statistics soft

\section{INTRODUCTION}

Genetically, reproductive functions are quantitative traits and are determined by numerous pairs of alleles or/ and non-allelic genes interactions which have generally and additive action. These functions are also influenced by environmental factors. (Duru, 2012, Forar, 1996). The etiology of genetically determined abortions was examined in numerous studies: McFeely 1968, Rommel 1960, Hansen 1974, Rugiati and Fedrigo 1968, Gustavsson 1971, Ghavi Hossein-Zadeh, 2013, Zobel, 2013).

The greatest risk of foetal losses is during the first trimester of gestation. It decreases progressively as gestation advances with a slight increase in the risk toward the last month of gestation (Thurmond, et al., 1990).

The observed fetal losses is less than the actual incidence. The cumulative incidence of fetal losses between 31 and 260 days of gestation is $10.8 \%$. A proportion of $20 \%$ of the fetal losses are recorded by observation. The proportion detected increases with increasing gestational age at time of fetal loss. Kinsel, 1999 identified a lesser incidence of $2.9 \%$ abortion (3012 lactations out of 103396) and a detection rate of $45.8 \%$ (1380 out of 3012). Also, it is proved that the abortion rate increases after 5 pregnancies or after 4 calvings and the risk is higher for a cow that already had an abortion.

Only 30\% of abortions' causes are identified. The causes of most abortions remain unknown, the endemic rates being about $10 \%$. The diagnostic success rate of bovine abortions detected by laboratories is about $40 \%$.

The above mentioned studies explain the necessity of fetal loss as a natural process which helps natural selection by eliminating inadequate genotypes.

Genetic factors which are involved in embryonic losses determine approximately $60 \%$ of the abortions which occur in the first four months of cows' pregnancies. Clinically, there are three main classes of abnormalities: re-arrangements in the configuration of parental chromosomes (Robertsonian translocation), non-separation of the pairs of the homologous chromosomes at the 
end of the primary meiosis and the nondisjunction phenomenon in the end of the secondary meiosis manifested by the non-disjunction o the sister chromatides (Griffiths 2000, Harlt, 1988, Klug, 2006). Approximately $40 \%$ of embryo-fetal losses are generated by mutant genes and / or mutant polygenic complexes.

Due to the fact that pregnancy represents the genetic interaction of three individuals: the mother, the father and the fetus, we can conclude that the genetic causes of embryo-fetal mortality can intervene in the metabolic functions of the mother or of the embryo, or, in rare cases, by physiological disturbances of paternal origin. In this context the inheritance of the embryo-fetal losses predisposition may be considered, both on the female or on the male origin. There it was emphasized and hereditary determinism related to the hormonal disorders in cows which may be important causes of the embryo-fetal losses. The investigations regarding the metabolic profiles in cows lead to some positive correlations in the couples mother-daughter in some indexes which reflect metabolic disorders which may be involved in the etiology of the embryo-fetal losses (Lothammer 1975).

Bulman (1979) proves the influence the male has on embryonic mortality by showing that the losses range between $11 \%$ and $14 \%$ depending on the sperm's provenience.

In addition, the inbreeding rate of the genitors was also demonstrated as an important cause of the embryo-fetal mortality. So, Hawk, 1955, proved that the embryonic mortality in the case of inbred lines was $28.4 \%-26.7 \%$, and for non-inbred lines was $13.3 \%$.

\subsection{Heritability}

In this context, heritability is a measure of the degree (0 to $100 \%$ ) to which offsprings resemble their parents for a specific trait. Heritability measures the strength of the relationship between performance (phenotype) and breeding value (genotype) of an individual animal. (Wu, 2007). Heritability tells the breeder how much confidence to place in the phenotypic performance of an animal when choosing parents of the next generation. For highly heritable traits where h2 exceeds 0.40 , the animal's phenotype is a good indicator of genetic merit or breeding value. For lowly heritable traits, where $\mathrm{h}^{2}$ is below 0.15 , an animal's performance is less useful in identifying the individuals with the best genes for the trait.
Heritability is one of the most important concepts in animal breeding. There are several working definitions for heritability: it helps plan breeding programs, determine management strategies, estimate breeding values of individual animals and predict response to selection.

The variance of a trait $\mathrm{x}$ is the average squared deviation of $\mathrm{x}$ from its mean

$$
\mathrm{V}_{\mathrm{p}}=\frac{\sum\left(\mathrm{x}-\overline{\mathrm{x}}^{2}\right.}{\mathrm{n}} \mathrm{V}_{\mathrm{p}}=\frac{\sum\left(\mathrm{x}-\overline{\mathrm{x}}^{2}\right.}{\mathrm{n}} .
$$

The total phenotypic variance can be splitted into genetic and environmental components: $\mathrm{V}_{\mathrm{P}}=\mathrm{V}_{\mathrm{G}}+\mathrm{V}_{\mathrm{E}}$. Genetic variance is the variance among phenotypes caused by genotypic differences among individuals. Environmental variance is the variance among phenotypes caused by differences in the experiences of individuals. The genetic variance can be expressed as $V_{G}=V_{A}+V_{D}$, where $V_{A}$ and $V_{D}$ are respectively additive and dominance components. The additive genetic variance is the part that makes offspring looking alike their parents.

The broad sense heritability denoted by $\mathrm{H}^{2}$ is defined as:

$$
\mathrm{H}^{2}=\frac{\mathrm{v}_{\mathrm{G}}}{\mathrm{V}_{\mathrm{P}}} \mathrm{H}^{2}=\frac{\mathrm{v}_{\mathrm{G}}}{\mathrm{V}_{\mathrm{P}}} .
$$

The narrow-sense heritability is the fraction is:

$$
\mathrm{h}^{2}=\frac{\mathrm{v}_{\mathrm{A}}}{\mathrm{v}_{\mathrm{P}}} \mathrm{h}^{2}=\frac{\mathrm{v}_{\mathrm{A}}}{\mathrm{v}_{\mathrm{P}}} .
$$

Heritability $h^{2} h^{2}$ determines the resemblance of offspring to their parents, and the population's evolutionary response to selection. $h^{2} h^{2}$ is the regression of offspring on parents. The higher the slope, the better the offspring trait values are predicted by parental trait values.

$$
h^{2}=2 b,
$$

where

$$
\mathrm{b}=\frac{\sum x-\frac{\sum x \sum y}{n}}{\sum x^{2}-\frac{\left(\sum x\right)^{2}}{n}}
$$


where: $\mathrm{n}$ - the number of daugthers in each family, $x$ - the values of the mothers, $y$ - the values of the daughters.

\subsection{Genetic and Environmental Correlations}

The correlation between parent and offspring is a procedure of measuring the genetic and environmental relationships among characters.

Many characters are positively or negatively correlated at the level of phenotype and they can be directly measured by the phenotypic correlation, $\mathrm{r}_{\mathrm{p}}$, between two traits $\mathrm{X}$ and $\mathrm{Y}$. The phenotypic correlation $r_{p}$ between two traits is generated by correlations between the genetic $\left(r_{A}\right)$ and/or environmental $\left(r_{E}\right)$ values of $X$ and $Y$. The $r_{A}$ correlation results from two sources: pleiotropic effects of loci on both traits and linkage disequilibrium. The $r_{E}$ correlation of environmental deviations results from exposure of the two traits to the same individual environment. Also, it includes non-additive genetic effects.

The correlation between traits $\mathrm{X}$ and $\mathrm{Y}$ equals with:

$$
r=\frac{\operatorname{cov}(X, Y)}{\sigma_{x} \sigma_{y}} r=\frac{\operatorname{cov}(X, Y)}{\sigma_{x} \sigma_{y}},
$$

where $\operatorname{cov}(\mathrm{X}, \mathrm{Y})$ represents the covariance. The covariance measures the common variant of two or more features and it is estimated by the average of the deviation's products. The covariance between the trait in two relatives provides an estimate of the additive genetic variance of that trait. The components of the phenotypic covariance are: the covariance of traits $\mathrm{X}$ and $\mathrm{Y}$ between sires

$$
\operatorname{cov}(X, Y)=\frac{1}{4} \operatorname{cov}_{A} \operatorname{cov}(X, Y)=\frac{1}{4} \operatorname{cov}_{A},
$$

the variance between sires of trait X,

$$
\sigma_{S X}^{2}=\frac{1}{4} \sigma_{A X}^{2} \sigma_{S X}^{2}=\frac{1}{4} \sigma_{A X}^{2}
$$

and the variance between sire of trait $Y$,

$$
\sigma_{S Y}^{2}=\frac{1}{4} \sigma_{A Y}^{2} \sigma_{S Y}^{2}=\frac{1}{4} \sigma^{2}{ }_{A Y} .
$$

In conclusion, it results that:

$$
r_{A}=\frac{\operatorname{cov}(X, Y)}{\sigma_{S X} \sigma_{S Y}} r_{A}=\frac{\operatorname{cov}(X, Y)}{\sigma_{S X} \sigma_{S Y}} \text {. }
$$

If a character is measured in two environments, we can take as two characters: $\mathrm{X}$ in environment one and $\mathrm{Y}$ in environment two.
This study shows the way in which embryonic mortality and fetal losses are inherited from mother to offspring. In addition, it also highlights the extent to which the father can be responsible for the existence of such losses in his partners and daughters.

\section{MATERIALS AND METHODS}

The study that was made in order to emphasize the way embryo-fetal losses are transmitted from mother to offspring and to in order to highlight the influence of the father in these processes was carried out on 823 cows representing the parental generation (mothers-P) and three offspring generations (F1, F2, F3). In the study, 5059 pregnancies were analyzed obtained from 823 mother cows (Hriţcu, 1987). Out of the 608 cows from the offspring generations (F1, F2, F3), 517 belong to families of paternal sisters. The number of members in the families varies from 4 to 115 cows. The average number of family of half-sisters members is 27.21 cows. These were divided in three groups: normal pregnancies, pregnancies interrupted by embryonic death and pregnancies interrupted by fetal abortion. The analysed gestations belong, both to the category of clinical diagnose gestation and also to the category of the prolonged sexual cycles, the cows being monitored until the end of the 5-th gestation, clinically diagnosed. Cow's distribution and the gestation's categories by generations are presented in Table 1. The distribution of the cows in the family of paternal half-sisters is presented in Table 2.

The link between embryonic mortality in mothers versus embryonic mortality in their daughters was analyzed using the mother-daughter correlation coefficient. Two separate components of embryonic mortality were analyzed: embryofetal losses and fetal abortions.

In order to establish the inheritance predisposition for the embryonic mortality trait the regression of offspring on dam method was applied.

In order to study the maternal and paternal influence on the embryo-fetal losses the relative multiple regression method was applied to a number of 517 cows belonging to 19 families of paternal half-sisters.

It was also made a comparative study of the 517 cows belonging to the above mentioned 19 families of half sisters in the case of 3196 
Tab.1. Cow's distribution and gestation's categories by generations

\begin{tabular}{lccccc}
\hline \multirow{2}{*}{ Generation } & \multirow{2}{*}{$\begin{array}{c}\text { Number } \\
\text { of cows }\end{array}$} & Total & Normal & Embryonic mortality & $\begin{array}{c}\text { Fetal } \\
\text { abortions }\end{array}$ \\
\cline { 3 - 6 } & 215 & 1300 & 1010 & 233 & 57 \\
\hline P & 377 & 2454 & 1653 & 636 & 167 \\
\hline F1 & 191 & 1089 & 801 & 193 & 95 \\
\hline F2 & 40 & 216 & 150 & 41 & 25 \\
\hline Total & 823 & 5059 & 3614 & 1103 & 344 \\
\hline
\end{tabular}

Tab. 2. Cow's distribution in families of paternal half-sisters

\begin{tabular}{|c|c|c|}
\hline Fam no. & Bull id & Number of daughters $n$ \\
\hline 1 & 8339 & 115 \\
\hline 2 & 10369 & 71 \\
\hline 3 & 9482 & 67 \\
\hline 4 & 8413 & 55 \\
\hline 5 & 8388 & 36 \\
\hline 6 & 22 & 31 \\
\hline 7 & 8393 & 30 \\
\hline 8 & 55 & 25 \\
\hline 9 & 8386 & 17 \\
\hline 10 & 9484 & 9 \\
\hline 11 & 77 & 9 \\
\hline 12 & 377 & 9 \\
\hline 13 & 9246 & 9 \\
\hline 14 & 78 & 9 \\
\hline 15 & 9490 & 6 \\
\hline 16 & 453 & 6 \\
\hline 17 & 8408 & 5 \\
\hline 18 & 9513 & 4 \\
\hline \multirow[t]{2}{*}{19} & 8412 & 4 \\
\hline & & 517 \\
\hline
\end{tabular}

pregnancies with that of 3043 gestations of the other partners of the same 19 bulls.

In order to emphasize the sources of genetic variations regarding the embryonic mortality recorded in the daughters in the frame of the 19 studied families, it was comparatively analyzed the situation of these losses to each partner of each bull, to the mother cows and to their daughters. So that the Wilcoxon test was applied on pair samples in order to study the frequency of the embryo-fetal losses recorded in daughters comparatively with the losses recorded in the partners of the same studied bulls. Also, the Wilcoxon test was used in order to process the embryo-fetal losses in the case of the couple mother cow- other partners of the studied bulls.

The influence of the bulls over the embryofetal losses was established analyzing the variation of the embryo-fetal losses recorded in cows mating with different bulls using one-way Anova analysis.

The genetic determinism in the case of the embryo-fetal losses in the frame of the 19 families of paternal half sisters was estimated using the heritability coefficient $h^{2}$. In order to find the $h^{2}$ value the regression method offspring-parent was applied in the case of the above mentioned 19 families of paternal half sisters, each family having a number of members varying between 9 and 115 . 
This method is based on the regression of the daughters traits compared to the values recorded in mothers related to the same trait.

The statistics was made using linear regression option from Rcmdr package in R statistics software.

\section{RESULTS AND DISCUSSIONS}

The values of correlations mother-daughter regarding the embryonic losses and fetal abortions related to the total number of the gestations are $r_{1}=0.94$ and $r_{2}=0.97$.

The phenotypic covariance in the fetal abortion trait in the relation mother-daughter is 0.06 and in the case of embryo-fetal losses is 0.002 .

Analyzing the regression made over the embryo-fetal losses trait related to the total numbers of couples mother-daughter is obtain intercept $=5.28, \mathrm{~b}=0.96 \pm 0.08$ and $\mathrm{p}$-value $=1.056 \mathrm{e}$ $09<0.05$ (Figure 1).

The multiple linear regression applied in the study of maternal-paternal influence on embryo-fetal losses of daughters reveals $\mathrm{p}=1.614 \mathrm{e}-08<0.05$. This value indicate that we can reject the null hypothesis that mother and father together have no effect on embryofetal losses of daughters. The results $p=5.81 \mathrm{e}-09<0.05$ also indicate that mother's embryo-fetal losses are significant controlled by the father.

In the case of fetal abortions study, we obtain for the intercept coefficient the value 1.13, $b=1.25 \pm 0.07$ with $p$-value $=3.699 \mathrm{e}-12<0.05$.

The maternal-paternal influence on daughter's fetal abortions provides a -value $=6.771 \mathrm{e}-11<0.05$ which indicate that we can reject the null hypothesis that the both parents have no effect on daughters (Figure 2.)
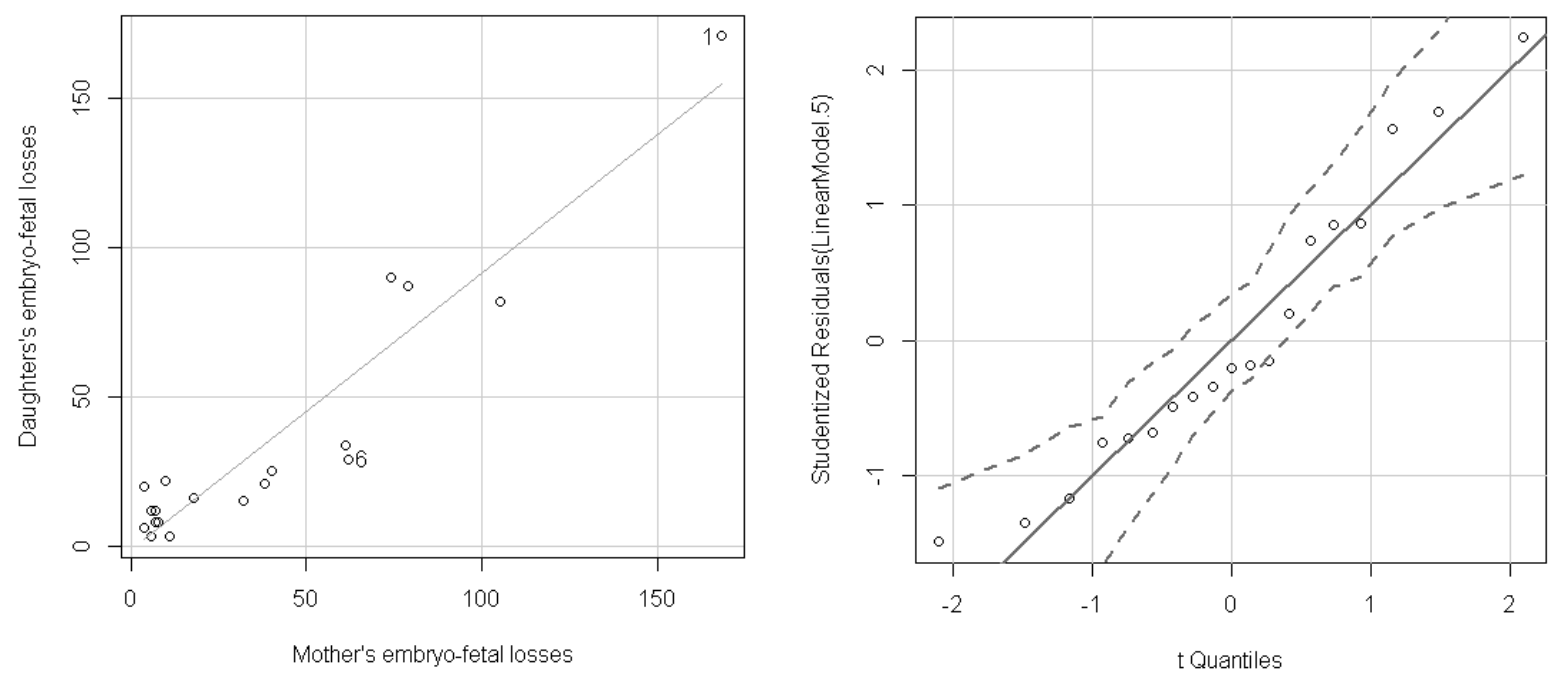

Fig. 1. Regression line of embryo-fetal losses in the case of couples mother-daughter
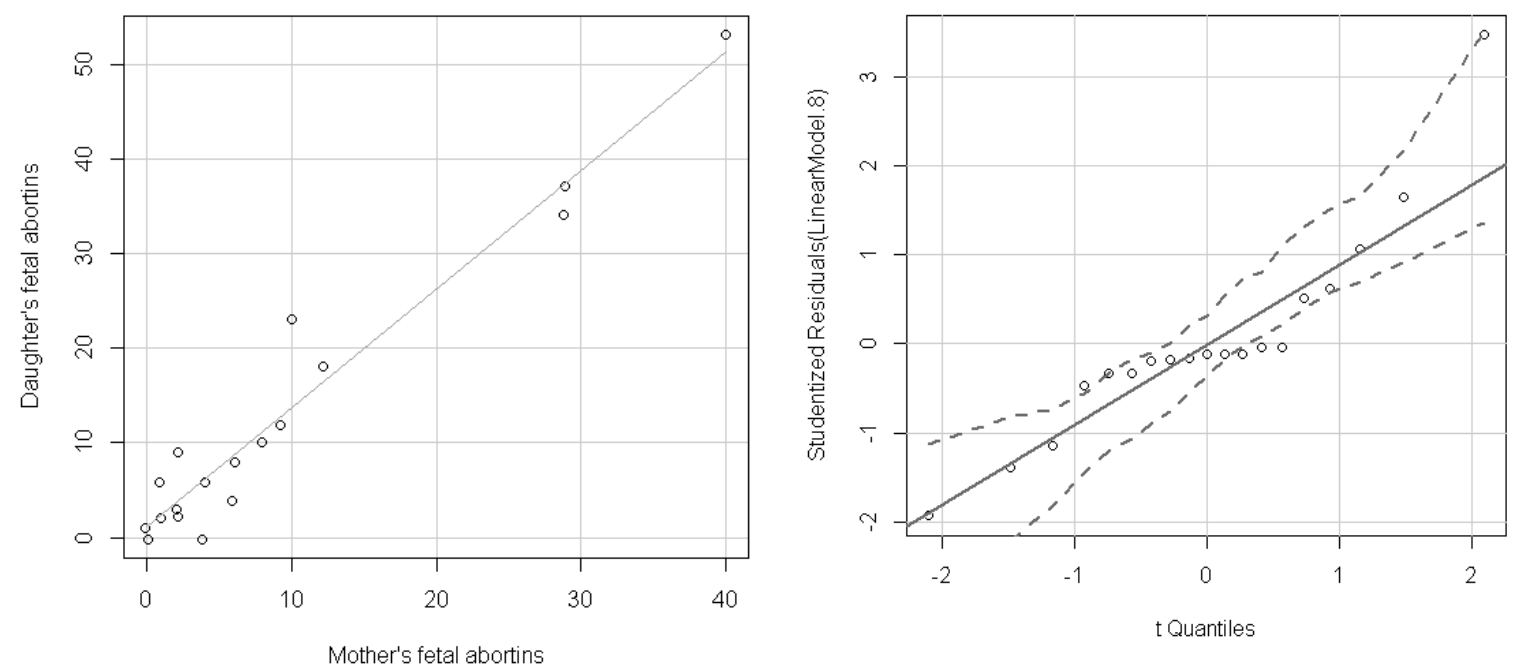

Fig. 2. Regression line of fetal abortions in the case of couples mother-daughter 
Tab. 3. The average number of embryonic losses and fetal abortions in the bulls' partners mother cows and daughter cows.

\begin{tabular}{lccc}
\hline Trait & Partners & Mother cows & Daughter cows \\
\hline Fetal abortions & 8.63 & 8.73 & 12.10 \\
\hline Embryonic losses & 34.26 & 34.94 & 38.94 \\
\hline
\end{tabular}

Tab. 4. Average number of embryo-fetal losses recorded in cows mated with different bulls.

\begin{tabular}{rrc}
\hline Fam no. & Bull id & Average number of embryo-fetal losses \\
\hline 1 & 8339 & $153.66 \pm 27.46$ \\
\hline 2 & 10369 & $79.33 \pm 7.50$ \\
\hline 3 & 9482 & $80.33 \pm 8.50$ \\
\hline 4 & 8413 & $85.00 \pm 18.68$ \\
\hline 5 & 8388 & $47.33 \pm 13.50$ \\
\hline 6 & 22 & $44.00 \pm 16.70$ \\
\hline 7 & 8393 & $30.66 \pm 8.14$ \\
\hline 8 & 55 & $27.00 \pm 9.53$ \\
\hline 9 & 8386 & $22.00 \pm 8.88$ \\
\hline 10 & 9484 & $16.33 \pm 1.52$ \\
\hline 11 & 77 & $14.00 \pm 8.71$ \\
\hline 12 & 377 & $13.66 \pm 7.23$ \\
\hline 13 & 9246 & $13.66 \pm 7.63$ \\
\hline 14 & 78 & $12.66 \pm 8.08$ \\
\hline 15 & 9490 & $13.66 \pm 8.62$ \\
\hline 16 & 453 & $10.33 \pm 9.29$ \\
\hline 17 & 8408 & $10.00 \pm 6.55$ \\
\hline 18 & 9513 & $6.00 \pm 2.64$ \\
\hline 19 & 8412 & $5.33 \pm 2.08$ \\
\hline
\end{tabular}

Tab. 5. The heritability coefficients of the embryo-fetal losses, fetal abortions and embryonic mortalities

\begin{tabular}{lc}
\hline Trait & $\mathrm{h}^{2}$ \\
\hline Embryo-fetal losses from clinically diagnosed gestations & 0.53 \\
\hline Fetal abortions from clinically diagnosed gestations & 0.34 \\
\hline Embryonic mortalities from clinically diagnosed gestations & 0.43 \\
\hline
\end{tabular}

It was observed that from 6268 gestations obtained from the cows mated with 19 bulls, there were recorded embryo-fetal losses in $26.24 \%$ of the cases. The maternal and paternal influence on daughters is presented in Table 3.

Wilcoxon paired test for fetal abortions reveals in the case of couple daughters-partners the $\mathrm{p}$-value $=0.1254>0.05$, and in the couple mother cow-partners the p-value $=0.5372>0.05$. These results emphasize that there are not significant differences between the average number of fetal abortions in the daughters and in the partners of the studied bulls and also that there are no significant statistic differences between the number of the fetal abortions of the studied partners and of the mother cows related to the same mating bulls.

For the trait embryonic losses it results that there are no significant differences between the daughters and the partners of the studied bulls because $p$-value $=0.4809>0.05$ (Table 3 ). 
Analyzing the resulted data it can be noticed that, even the individual differences are recorded, these are not significantly reflected, regarding the statistics on the entire studied group. Considering this reason it is recommended to analyze individual the data which reflects the influence of each bull on reproduction (Table 4.).

The regression coefficient of the total embryofetal losses calculated for 608 couples motherdaughter is 0.26 . Related to different generations, the coefficient 0.32 is obtained between mother-F1 generation, 0.14 between $\mathrm{F} 1$ and F2 generation and 0.48 between F2 and F3.

The regression coefficient mother-daughter on categories of losses is 0.34 in the fetal abortions, varying between 0.31 (mother-F1) and 0.36 (F1-F2). Regarding the embryonic mortality the regression coefficient reported to the total gestations is 0.17 , varying from 0.24 (mother-F1), 0.06 (F1-F2) and 0.17 (F2-F3).

Applying the regression of offspring on dam method the values of the heritability coefficient were obtained which are presented in Table 5.

The obtained data reveals the fact that the incidence of the abortions is more incresed in cows in which abortions occur during their life. So, the study of the maternal influence is very important for the genetical prophylaxy of the abortions in cows.

The values of the corelation coefficients express a positive correlation mather-daughter regarding the embryonic mortality and embryofetal abortions. The number of embryo-fetal losses of the daughters is expressed using the mother embryo-fetal losses using the relation $y=5.28+0.96 x$. The daughter's embryo-foetal losses can be expressed with respect of both parents as $\mathrm{y}=5.26+0.96 \mathrm{x}_{1}-0.000045 \mathrm{x}_{2}$. The equation of the regression line which expresses the relation mother-daughter regarding the foetal abortions character is $y=1.13+1.25 x$.

In Table 4 is presented that in the cows matted with the bull with ID 8412 the number of the embryo-fetal losses was the lowest. One-way Anova analysis reveals the fact that there exists significant differences regarding the number of embryo-fetal losses in cows mated with bull with ID 8412 and the number of embryo-fetal losses regarding the same cows mated with bulls with the 8339, 10369, 9482, 8413, 8388 and 22. So, briefly there were noticed influences also form the reproductive bulls which must be considered individual.

The regression coefficient for the couples mother-daughter shows that a variation of $1 \%$ of the incidence of the embryo-fetal losses in mothers determine a variation of $24 \%$ of the same kind in their daughters. In the case of the fetal abortions a variation of $1 \%$ in mothers induce a variation of $31 \%$ in their daughters. Concluding, we can say that the incidence of the fetal abortions is more influenced by the mother compared to the embryonic mortality.

The values presented in table 5 related to the heritability coefficients of the embryo-fetal losses embryonic mortality shows a strong genetic determinism. The fetal abortions present a weaker genetic determinism, expressed by the heritability coefficient of 0.34 . So, we can also add that $34 \%$ of phenotype variance of fetal abortions is determined by additive effect of the genes, respectively $43 \%$ of the trait embryonic mortality.

\section{CONCLUSIONS}

The main important conclusion is that the criteria for the evaluation of the bulls for reproduction must include beside the quality of the sperm the incidence of the embryo-fetal losses to the mother cows and their daughters.

The main recommendation for the farmers and veterinarians is to focus also on prevention and control of the risk factors associated with reproductive problems than on therapeutics.

\section{REFERENCES}

1. Bulman DC (1979), A possible influence of the bull on the incidence of embryonic mortality in cattle. The Veterinary Rec, 3: 420-425.

2. Duru S, Kumlu S, Tuncel E (2012) Estimation of variance components and genetic parameters for type traits and milk yield in Holstein cattle. Turk J Vet Anim Sci, 36(6): 585-591.

3. Forar AL, Gay JM, Hancock DD. (1996) Fetal loss in ten Holstein dairy herds. Theriogenol.; 45: 1505-1513.

4. Ghavi Hossein-Zadeh H. (2013) Effects of main reproductive and health problems on the performance of dairy cows: a review. Spanish Journal of Agricultural Research; 11(3): 718-735.

5. Griffith AJF, Miller JH, Suzuki DT, Lewontin RC, Gelbart WM. (2000) An Introduction to Genetic Analysis. Seventh Edition. Ed. W.H. Freeman.

6. Gustavsson I. (1971) Culling rates in daughters of sires with a translocation of centric fusion type. Hereditas; 67: 65-74. 
7. Hansen KM, Elley F. Chromosome investigation of Danish A.I. beef bulls. Nord Vet. Med. 1975; 27(2): 315-317.

8. Hartl DL, Freifelder D, Snyder LA. (1988) Basic Genetics. Jones and Bartlett Publishers;

9. Hawk HW, Wiltbank JN, Kidder HE, Casida LE. (1955) Embryonic mortality between 16 and 34 days post breeding in cows of low fertility. J. Dairy Sci.; 38: 673-676.

10. Hrițcu V. (1987) Contribuţii la studiul mortalitatiii embrionare si al avorturilor la vaci. Institutul agronomic "Ion Ionescu de la Brad" Iasi, Romania,

11. Kinsel ML. (1999) An epidemiologic approach to investigating abortion problems in dairy herds. Proc. Am. Assoc. Bov. Pract.; 32: 152-160.

12. Klug WS, Cummings M, Spencer CA. (2006) Concepts of Genetics. Pearson Education Inc;.

13. Lothammer KH. (1975) Correlation between calf deseas and nutrition with some blood parameters in cows. In: Perinatal ill-health calves. J.M. Rutter Ed.; 159-167.
14. Mc.Feely RA, Merrit AM, Steraly EL. (1977) Abortion in a dairy held vaccinated for infectious bovine rhinotracheitis. Am Vet Med Assoc 1968; 153(6):657-661.

15. Rommell GM. (1960) Essentials of animal breeding. Farmers's Bulletin, Published by US Department of Agriculture.

16. Rugiati S, Fedrigo M. (1967) Alterazione cromosomica riscontrata in un toro acondroplasico di razza Romagnola. L'Atenco Parmense. Acta Bio. Medica, 38: 3-7.

17. Thurmond MC, Picanso JP. (1990) A surveillance system of bovine abortion. Prev. Vet. Med. 8: 41-53.

18. Vlaic A. (2011) Genetica Animala. Ed. AcademicPres, ClujNapoca, Romania.

19. Zobel R, Tkalac S, Cole W. (2013) Fertility issues in Simmental cows in Central Croatia: a 5-year study. Turk. J. Vet. Anim. Sci., 37: 454-464.

20. Wu R, Ma CX, Casella G. (2007) Statistical Genetics of Quantitative Traits. Springer. 